\title{
Systematic Literature Review to Assess Economic Evaluations in Spinal Muscular Atrophy (SMA)
}

\author{
Noman Paracha ${ }^{1} \cdot$ Pollyanna Hudson ${ }^{2} \cdot$ Stephen Mitchell ${ }^{2} \cdot$ C. Simone Sutherland ${ }^{1}$ (1)
}

Accepted: 20 September 2021 / Published online: 18 October 2021

(c) The Author(s) 2021

\begin{abstract}
Background Spinal muscular atrophy (SMA) is a rare, progressive neuromuscular disease that affects individuals with a broad age range. SMA is typically characterised by symmetrical muscle weakness but is also associated with cardiac defects, life-limiting impairments in respiratory function and bulbar function defects that affect swallowing and speech. Despite the advent of three innovative disease-modifying therapies (DMTs) for SMA, the cost of DMTs in addition to the costs of standard of care can be a barrier to treatment access for patients. Health Technology Assessment (HTA) decision makers evaluate the cost effectiveness of a new treatment before making a reimbursement decision.

Objective The primary objective was to conduct a systematic literature review (SLR) to identify the modelling approaches used in economic evaluations that assess current approved treatments in SMA, with a secondary objective to widen the scope and identify economic evaluations assessing other (non-SMA) neuromuscular disorders.

Methods An SLR was performed to identify available economic evaluations associated with any type of SMA (Type 1, 2, 3 and/or 4). Economic evaluations associated with other (non-SMA) neuromuscular disorders were identified but not further analysed. Electronic searches were conducted in Embase, MEDLINE, Evidence-Based Medicine Reviews and EconLit via the Ovid platform in August 2019, and were supplemented by searches of the grey literature (reference lists, conference proceedings, global HTA body websites and other relevant sources). Eligibility criteria were based on the population, interventions, comparators and outcomes (PICO) framework. Quality assessment of full publications was conducted with reference to a published checklist.

Results Nine publications covering eight unique studies met all eligibility criteria for inclusion in the SLR, including four conference abstracts, two peer-reviewed original research articles and three HTA submissions (conducted in Canada, the US and the UK). Evaluations considered patients with early infantile-onset (most likely to develop Type 1 or Type 2 SMA), lateronset SMA and both infantile- and later-onset SMA. Data for the identified economic models were collected from literature reviews and relatively short-term clinical trials. Several intent-to-treat clinical trial populations were used in the studies, which resulted in variation in cycle length and different outcome measures to determine clinical efficacy. The results of the quality assessment on the five full-text, peer-reviewed publications found that they generally provided clear descriptions of objectives, modelling methods and results. However, key decisions, such as choice of economic evaluation, model type and choice of variables for sensitivity analysis, were often not adequately justified.

Conclusions This SLR highlights the need for economic evaluations in SMA to better align in modelling approaches with respect to (i) consistency in model structure and use of motor function milestones as health states; (ii) consensus on measuring quality of life to estimate utilities; (iii) consistency in data collection by registries; and (iv) consensus on SMA-type classification and endpoints that determine intervention efficacy. Future economic evaluations should also incorporate the review group critiques of previous HTA submissions relating to data inputs and approaches to modelling and should include patient data reflective of the SMA population being modelled. Economic evaluations would also be improved with inclusion of long-term efficacy and safety data from clinical trials and valid patient and caregiver utility data.
\end{abstract}

Extended author information available on the last page of the article 


\section{Key Points for Decision Makers}

The advent of three innovative disease-modifying therapies for spinal muscular atrophy (SMA) has led to a recent increase in economic evaluations, yet a lack of long-term clinical trial data remains a challenge.

Nine economic evaluations of SMA showed inconsistent methodological approaches, and recommendations by Health Technology Assessment bodies were generally not met.

Consensus for future economic evaluations in SMA should include standardised intervention efficacy endpoints and consideration of revised classification of SMA types.

\section{Introduction}

Spinal muscular atrophy (SMA) is a rare, hereditary, progressive neuromuscular disease that is a leading genetic cause of infant mortality, when untreated, and for which there is currently no cure $[1,2]$. In approximately $96 \%$ of cases, SMA is caused by homozygous deletions, or less frequently ( $\sim 4 \%$ of cases) deletions and mutations in the survival of motor neuron 1 (SMN1) gene [3]. Another SMN gene, $S M N 2$, produces SMN protein at insufficient levels to fully compensate for loss of $S M N 1$ function $[4,5]$. The $S M N 2$ copy number is inversely correlated with the severity of SMA [6, 7]; however, this correlation is not absolute due to additional genetic and epigenetic disease modifiers [8]. SMA, although a disease continuum, is classified into five types (0-4; most to least severe) [9-12] and SMA types differ with respect to survival and overall quality of life [13-16]. Type 0 SMA results in intrauterine or early neonatal death [9], whereas onset of Type 4 SMA occurs during adulthood and represents the least severe SMA type with the lowest incidence [17]. Type 1 SMA, clinically characterised by symmetrical skeletal muscle weakness, hypotonia and respiratory deficiency, results in death by 2 years of age in the majority of untreated infants $[14,18]$. More than $50 \%$ of individuals with Type 1 SMA require feeding support by 8 months of age due to compromised swallowing function [19] and, if untreated, would never be able to sit independently and would show a decline in motor function [14]. Individuals with Type 2 SMA can sit, but never walk, whereas individuals with Type 3 SMA are able to walk, but progressively lose the ability due to muscle weakness $[12,20]$.
A standard of care (SOC) for SMA management was established in 2007 to standardise the care of patients with SMA [21]. The SOC recommendations focussed on active respiratory management or acute care, and supportive or palliative treatments that had no ability to prevent motor neuron loss or improve muscle weakness [2, 21, 22]. The SOC recommendations for SMA management were updated in 2018; these recommendations reflect an extensive multidisciplinary approach to SOC including the expertise of neurologists, respiratory specialists, gastroenterologists, dietitians, physical therapists, geneticists, palliative care physicians and orthopaedic surgeons [15, 23]. It should be noted, however, that this update was developed prior to widespread approval of disease-modifying therapies (DMTs).

Better understanding of the underlying pathogenic process in SMA led to the development of novel DMTs that target the deficit of functional SMN protein using different molecular approaches. Nusinersen (SPINRAZA ${ }^{\circledR}$; Biogen Inc., Cambridge, MA, USA) was approved in the US by the Food and Drug Administration in 2016 [24] and in Europe by the European Medicines Agency in 2017 [25]. Onasemnogene abeparvovec-xioi (ZOLGENSMA ${ }^{\circledR}$; AveXis Inc., Bannockburn, IL, USA) was approved in the US and Europe in 2019 and 2020, respectively [26, 27], while risdiplam (EVRYSDI ${ }^{\circledR}$; Genentech Inc. a member of the Roche Group, South San Francisco, CA, USA) was approved in the US in 2020 [28] and in Europe on 30 March 2021 [29]. Nusinersen, onasemnogene abeparvovec and risdiplam differ according to route of administration, posology and maintenance regimens, and approved indication regarding SMA populations. Nusinersen, an intrathecally administered SMN2-targeting antisense oligonucleotide, designed to increase functional SMN production [30], requires four loading doses, then three maintenance doses per year for adult and paediatric patients of all SMA types [24, 25]. Onasemnogene abeparvovec is an intravenously administered adeno-associated virus vector-based gene transfer therapy that requires one dose to facilitate the transfer of a copy of the SMN1 gene [31]. Onasemnogene abeparvovec is approved in the US for patients aged $<2$ years with bi-allelic mutations in SMN1 [26] and in Europe for children with an inherited mutation in SMN1 and up to three copies of SMN2 [27]. Risdiplam is a daily, orally administered $S M N 2$ splicing modifier that promotes the inclusion of exon 7 and is distributed both centrally and peripherally [32]. Risdiplam is approved for patients of all SMA types aged $\geq 2$ months of age (US) [28] and for patients $\geq 2$ months of age with a clinical diagnosis of Type 1, Type 2 or Type 3 SMA or with 0-4 SMN2 copies (Europe) [29].

Clinical trials of nusinersen, onasemnogene abeparvovec and risdiplam have demonstrated clinically meaningful improvement for individuals with early- and later-onset 
SMA [33-40]; the benefits of DMTs are greater when treatment is initiated during the presymptomatic phase of SMA [41]. However, the cost of DMTs in addition to the costs of SOC can be a barrier to treatment access for patients with SMA [42, 43]. Similar barriers to treatment access also occur for other rare neuromuscular conditions such as Duchenne muscular dystrophy (DMD) [44]. Health Technology Assessment (HTA) decision makers rely on economic evaluations to determine the cost effectiveness of a new treatment before making a reimbursement decision [45]. Economic evaluations report the net costs of a novel medical intervention with respect to the net health benefits that the intervention yields, relative to a comparator such as SOC [46]. Conducting HTA assessments for rare diseases has many challenges, including the absence of a tailored HTA method for rare diseases $[47,48]$. The US Institute for Clinical and Economic Review (US ICER Group) has identified particular challenges that exist for assessing economic evaluations of treatments [49]; for example, a lack of robust methods for assessing health-related quality of life in young patients (often requiring the use of caregivers acting as proxies or data from general population samples), small sample sizes (resulting in large measures of variance and subsequent additional uncertainty in economic evaluation findings), a lack of robust and long-term clinical data across all SMA types, and cost-effectiveness estimates that exceed commonly cited thresholds [49].

The primary objective of this systematic literature review (SLR) was to identify the modelling approaches in economic evaluations that assess current approved treatments relevant to SMA, with a secondary objective to widen the scope and identify economic evaluations assessing other (non-SMA) neuromuscular disorders. We identify consensus and disparity between these models, as well as summarise the reported cost effectiveness of available DMTs for SMA.

\section{Methods}

\subsection{Search Strategy and Selection Criteria}

An SLR was performed to identify available economic evaluations associated with SMA. The Preferred Reporting Items for Systematic reviews and Meta-Analyses (PRISMA) 2020 guidelines [50] were followed to identify and screen scientific literature and extract data (Fig. 1).

A comprehensive search was performed on 29 August 2019 using the following electronic databases accessed via the Ovid platform: Embase, MEDLINE ${ }^{\circledR}$ (including Epub Ahead of Print, In-Process \& Other Non-Indexed Citations and Daily update), Evidence-Based Medicine Reviews and EconLit. Additional searches (hand searching) of congress proceedings from the past 3 years, reference lists of included publications, HTA bodies and searches of additional sources and websites, such as SMA UK, were also conducted to identify relevant evidence (electronic supplementary material [ESM] Table 1). Eligibility criteria included economic value analyses conducted in any patient with SMA (Type 1, 2, 3 and/or 4) and other (non-SMA) neuromuscular disorders. As it was anticipated that there would be a small number of relevant publications involving patients with SMA, the scope was initially broad to include patients with other (non-SMA) neuromuscular disorders including, but not limited to, myodystrophy, muscular dystrophy and amyotrophic lateral sclerosis. The search strategies, including database search start dates, are shown in ESM Table 2. Eligibility criteria were based on the population, interventions, comparators and outcomes (PICO) framework [51] to identify relevant data (ESM Table 3). Economic evaluation study designs included cost-utility, cost-effectiveness, cost-minimisation and cost-benefit analyses. There was no restriction regarding intervention, geography, language of publication, or publication date.

\subsection{Data Extraction}

Records were reviewed by a single reviewer based on title and abstract in the first instance, and included records were based on the full publication. A second reviewer checked the data extraction for accuracy and completeness; any inconsistencies were referred to a third reviewer and resolved through discussion.

\subsection{Assessment of Bias and Quality of Evidence}

Quality assessment of primary full publications was conducted using the National Institute for Health and Clinical Excellence (NICE) single technology appraisal specification for manufacturer submission of evidence (June 2012), as adapted from Drummond and Jefferson [52].

\section{Results}

The search of databases yielded 3276 records. Following removal of duplicates, 2898 citations were screened based on title and abstract. In total, 42 citations were deemed potentially relevant and 41 (one record not retrieved) underwent full-text review before 18 studies were further excluded based on PICO criteria. Of these, 11 studies considering other (non-SMA) neuromuscular disorders (ESM Table 4) and six studies considering the cost effectiveness of screening/diagnostic techniques for SMA (ESM Table 5) were not analysed further. Three additional potentially relevant records were identified via hand searching. Overall, nine 


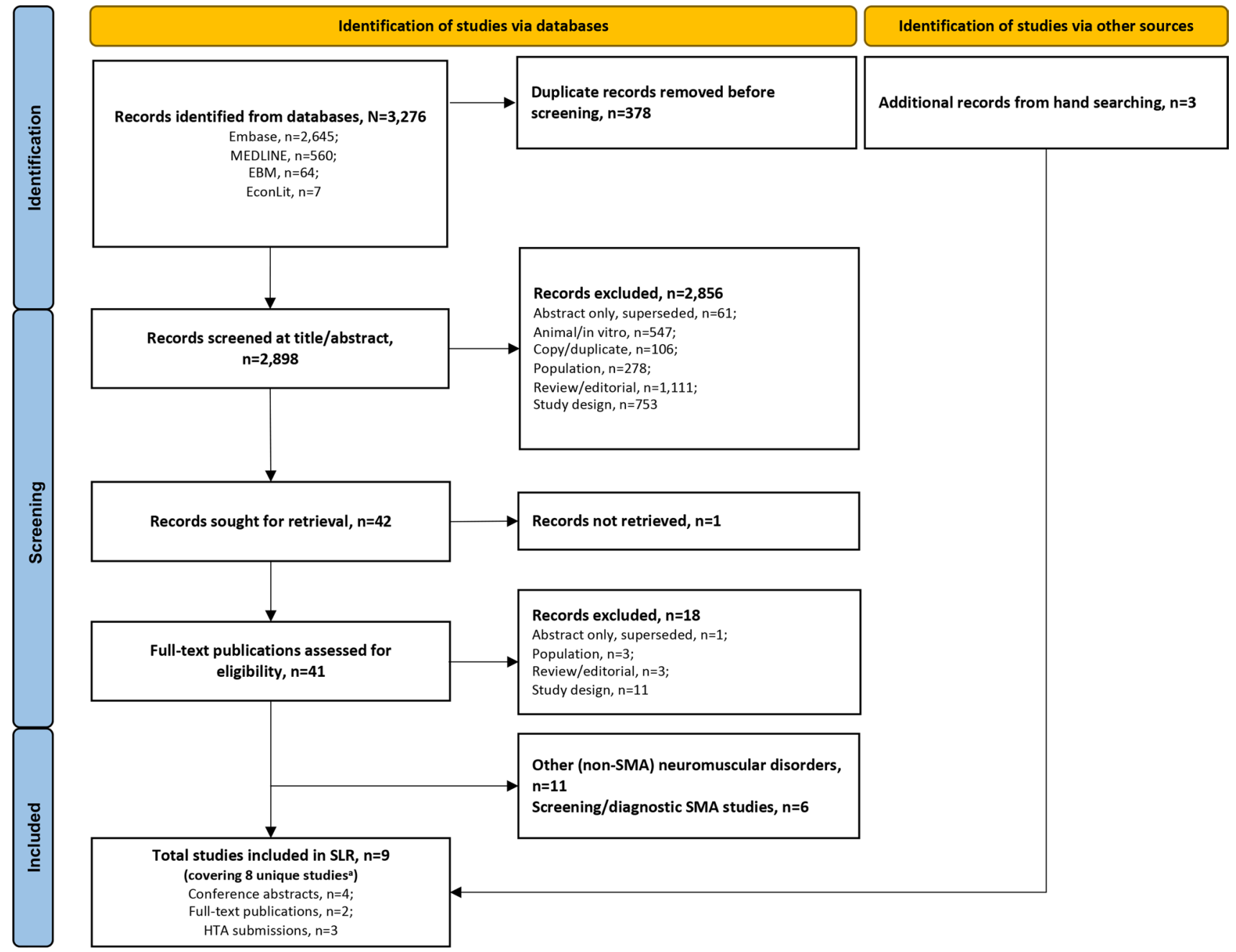

Fig. 1 PRISMA flow diagram of the selection process that identified nine publications, reporting economic evaluations in SMA that were included in this SLR. ${ }^{\mathrm{a}}$ One full publication and one conference abstract were linked studies; both have been retained in the current

publications covering eight unique studies met all eligibility criteria for final inclusion in this SLR (Fig. 1).

\subsection{Characteristics of Economic Evaluations}

\subsubsection{Cost-Utility Analysis Publication Types}

The nine publications included in this SLR comprised four conference abstracts [53-56], two peer-reviewed, original research articles $[57,58]$ and three distinct HTA submissions: one submission to the Canadian Agency for Drugs and Technologies in Health (CADTH) published in 2018 [59], one submission (TA588) to the UK NICE published in 2018 [60] and one submission to the US ICER Group report as they each report unique relevant data. EBM Evidence-Based Medicine Reviews, HTA Health Technology Assessment, SLR systematic literature review, SMA spinal muscular atrophy

published in 2019 [61]. The CADTH [59], NICE [60] and US ICER Group [61] HTA submissions comprised economic models from studies conducted in Canada, the UK and the US, respectively. There was some overlap between the identified published economic evaluations and HTA submissions: the published analysis by Zuluaga-Sanchez et al. 2019 [58] included a similar model to that submitted to NICE [60] and to CADTH [59]. Furthermore, the published analysis by Thokala et al. 2019 [54] included the model submitted to the US ICER Group [61]. All nine publications (including HTA submissions, abstracts and full manuscripts) that met the eligibility requirements of the literature search contained unique data and were therefore considered as discrete publications for the review. 


\subsubsection{HTA Submissions}

The HTA submission to CADTH compared nusinersen with SOC for patients with Types 1, 2 and 3 SMA [59]. The HTA submission to NICE assessed nusinersen compared with SOC for patients with infantile-onset (Type 1) and later-onset (Types 2 and 3) SMA [60]. The HTA submission to the US ICER Group examined nusinersen and onasemnogene abeparvovec, each compared with SOC for patients with SMA of all ages and SMA types [61].

\subsubsection{Conference Abstracts and Journal Articles}

Six economic evaluations, published as conference abstracts or journal articles, represented five studies conducted in the US [53-57] and one published economic evaluation reported a study conducted in Sweden [58]. Two publications based on a study conducted by the same research group in the US were published as an abstract [53] and a full-text publication [57]. The evaluations considered patients with early infantile-onset SMA (most likely to develop Type 1 or Type 2 SMA) $(n=4)[53-55$, 57], later-onset SMA $(n=1)$ [56] and both infantile- and later-onset SMA $(n=1)$ [58]. Treatment comparisons considered across the six published economic evaluations included nusinersen versus SOC [54-56], nusinersen + SOC versus SOC [58], onasemnogene abeparvovec versus SOC [54], onasemnogene abeparvovec compared with nusinersen + SOC [57] and onasemnogene abeparvovec compared with nusinersen as the SOC [53]. An incremental cost per quality-adjusted life-year (QALY) gained was reported in all six publications [53-58].

\subsection{Interventions and Comparator Definitions}

Interventions in this SLR refer to nusinersen or onasemnogene abeparvovec. In the nine publications, the comparator was typically described as SOC, although the terms best supportive care or real-world care were also used. For simplicity, herein we refer to SOC as the comparator assessed in all nine economic evaluation publications; additional information regarding comparators is listed in the footnotes of Table 1. For clinical trials involving nusinersen, SOC was with or without sham administration. Inclusion of SOC in addition to an intervention was assumed, although was not explicitly stated in Malone et al. 2019 [57] and ZuluagaSanchez et al. 2019 [58]. Malone et al. 2019 [53] was the only publication in which nusinersen treatment was considered as the SOC for comparison with the intervention onasemnogene abeparvovec. This has been highlighted in Table 1 to avoid confusion with the definition of SOC in the remainder of this manuscript, which does not include treatment with an approved DMT.

\subsection{Modelling Methodology}

\subsubsection{Model Outcomes, Perspectives, Discounting and Time Horizon}

To estimate costs and benefits, the CADTH [59] and NICE [60] HTA submissions used a Markov approach, while the US ICER Group [61] HTA submission used a partitioned survival approach. The models presented in the CADTH [59] and NICE [60] HTA submissions were developed by Biogen Inc. and the CADTH [59] model structure is also described in Zuluaga-Sanchez et al. 2019 [58]; these analyses examined nusinersen versus SOC. The model developed in Malone et al. 2019 [57] that compared nusinersen and onasemnogene abeparvovec and was reviewed by the US ICER Group [61] was funded by AveXis, Inc (Novartis).

All three HTA submissions adopted a payer perspective and discounting was performed in accordance with countryspecific (Canada, US and UK) requirements for both costs and benefits (ranging from 1.5 to 3.5\%) [59-61] (Table 1). The HTA submission to NICE adopted a health and social care perspective in the base case and considered the societal perspective in a scenario analysis [60]. In the nine studies, the payer perspective included the Canadian health care system [59], the US health care sector [54, 61], US commercial payer [57], US third-party payer [55, 56], the UK National Health Service (NHS) reference costs and published literature for general health management costs [60] and the Swedish societal perspective [58]; one study did not report the perspective [53]. A discount rate of $3.0 \%$ costs and benefits per annum was used in five studies [53, 54, 57, 58, 61], while the HTA submissions to CADTH and NICE used 1.5\% [59] and $3.5 \%$ [60], respectively, and two studies did not report discount rates $[55,56]$.

The time horizons of the nine publications included in this SLR ranged from 25 years to lifetime and were dependent on whether early-onset or later-onset models were used (Table 1). Early-onset models had a time horizon of 25 years to lifetime, and later-onset models had a time horizon of 80 years to lifetime. The difference in time horizons between early-onset and later-onset models reflected the shorter survival time in patients with Type 1 SMA compared with patients with Types 2, 3 and 4 SMA [12].

\subsubsection{Model Health States and Survival}

Data for the identified economic models were collected from literature reviews and relatively short-term clinical trials. Several intent-to-treat clinical trial populations were used in the studies, which resulted in patient populations of different 


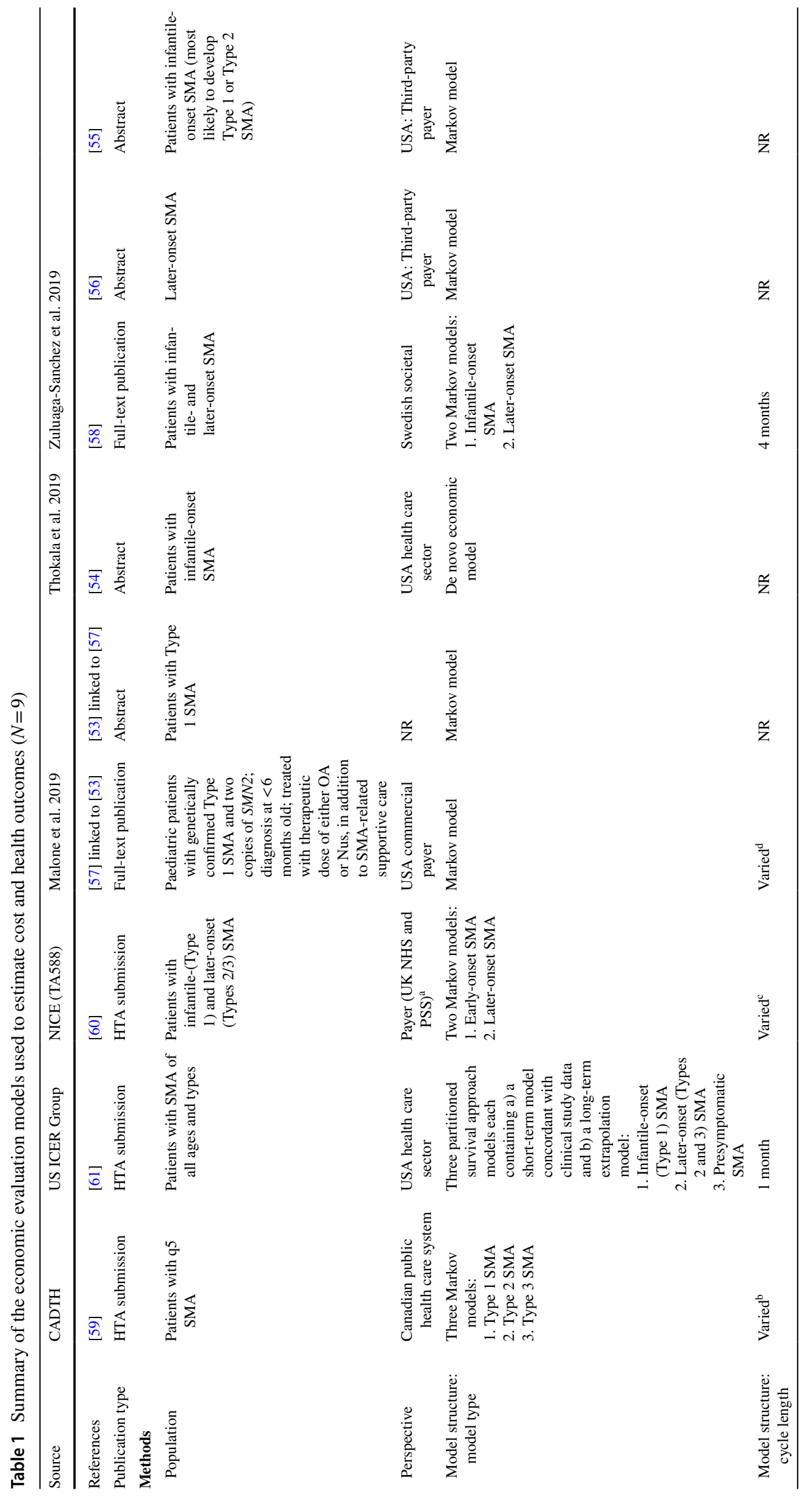




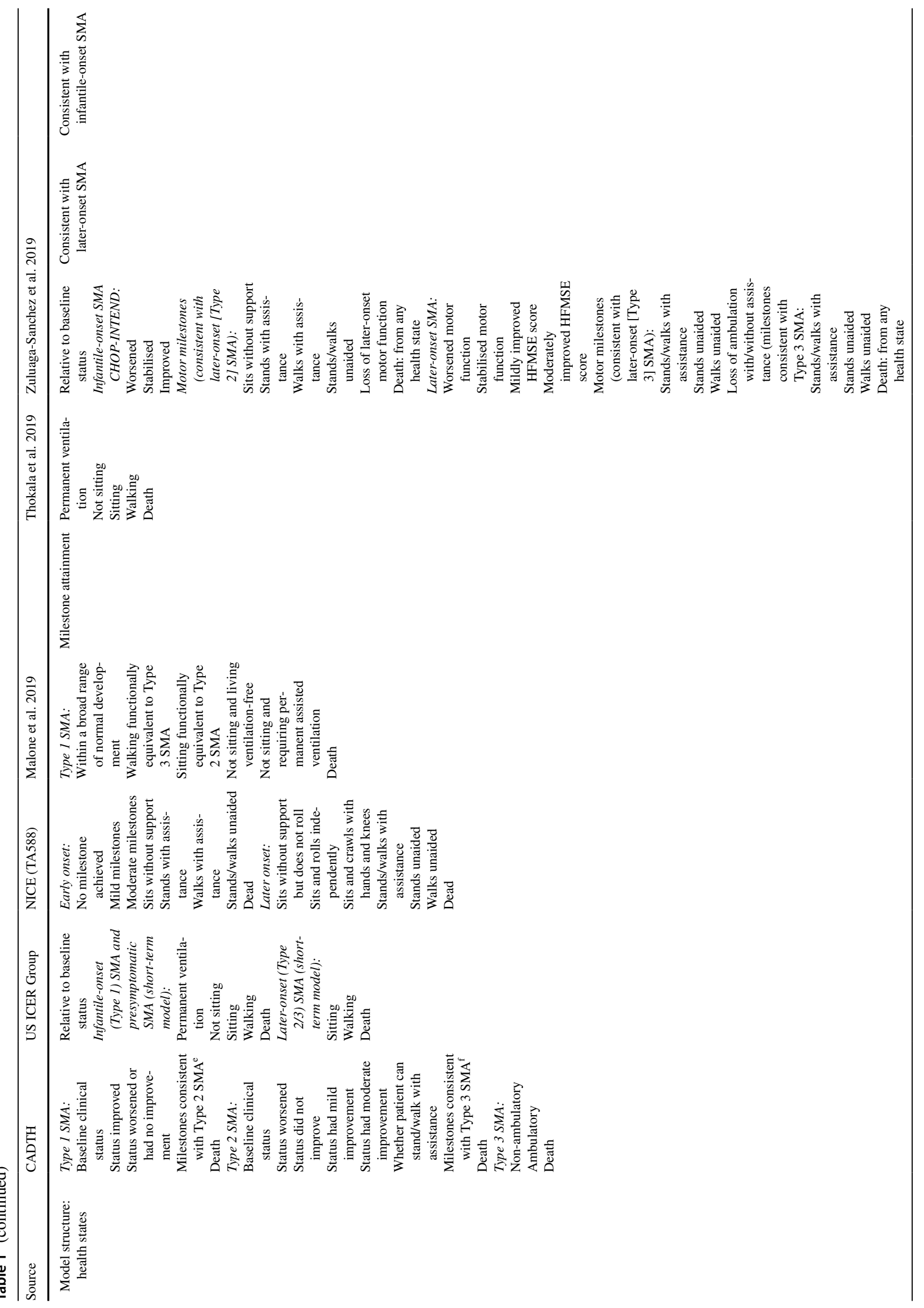




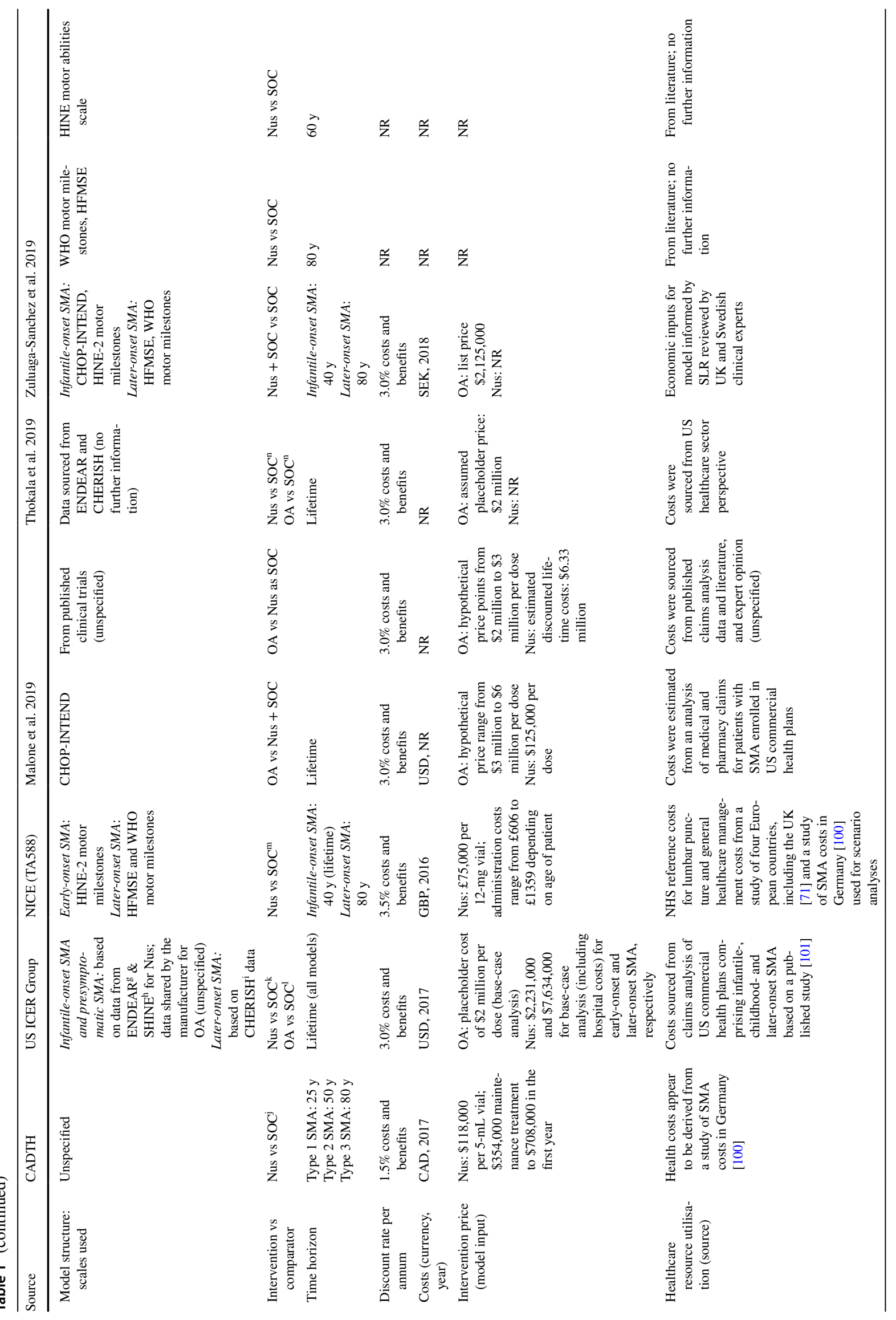




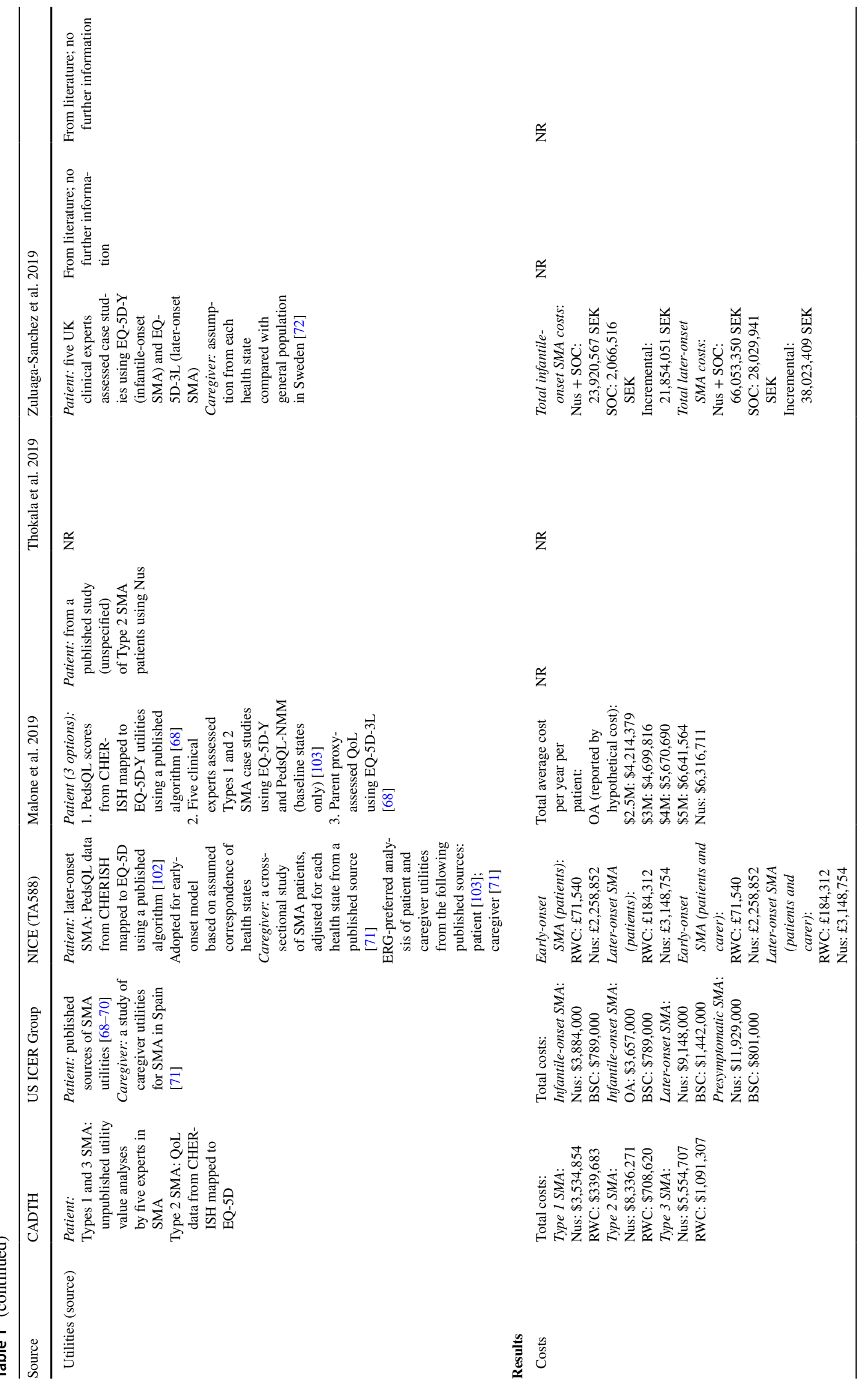




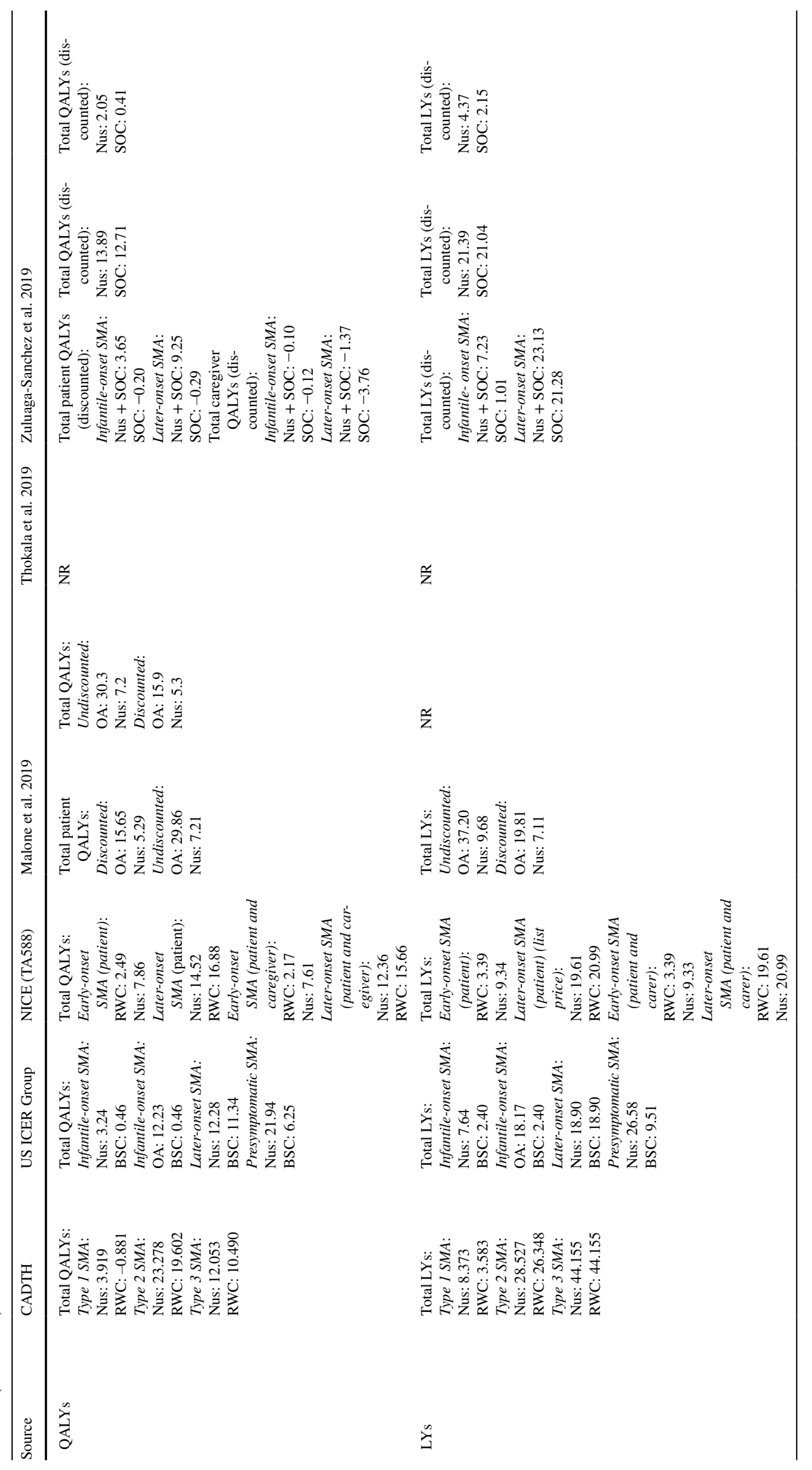




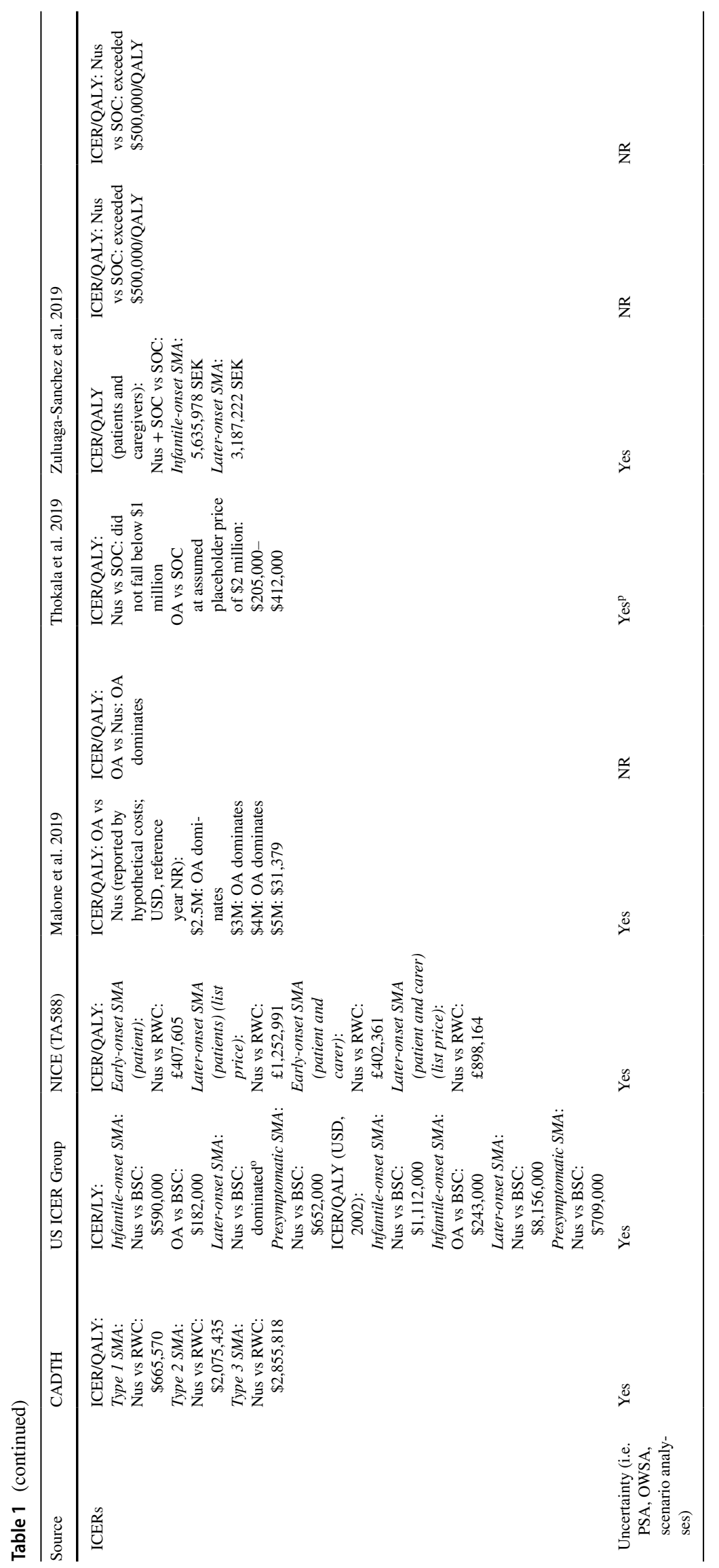




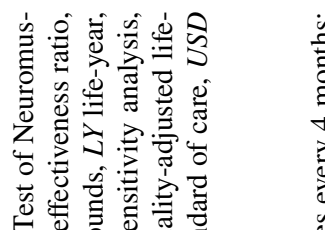

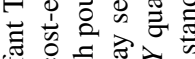

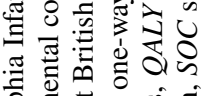

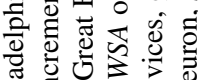

弯. $\begin{aligned} & 0 \\ & 0\end{aligned}$

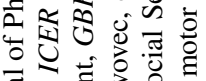

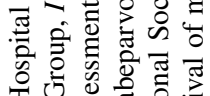

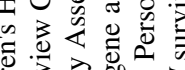

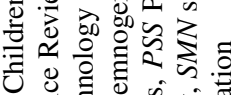

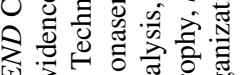

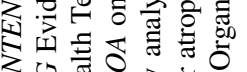

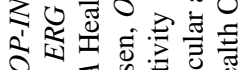

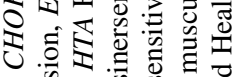

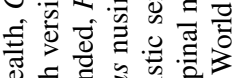

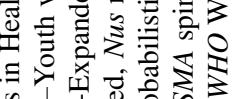

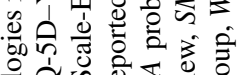

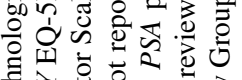

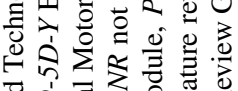

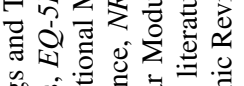

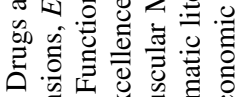

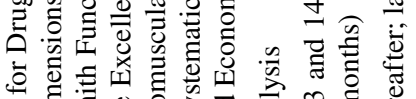

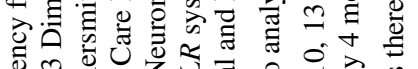

के 0

《论

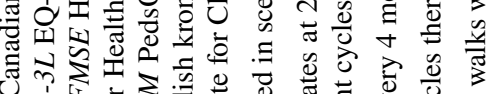

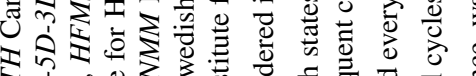

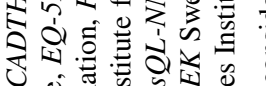

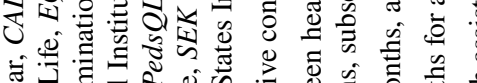

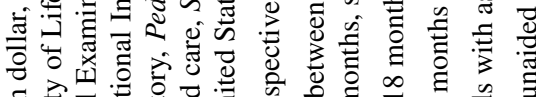

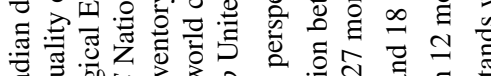

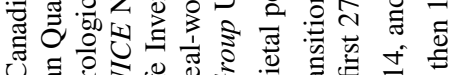

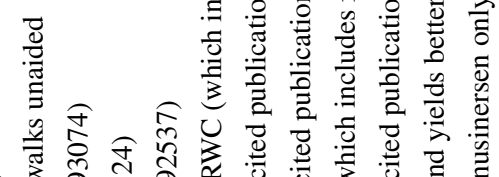

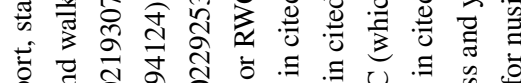

Uी

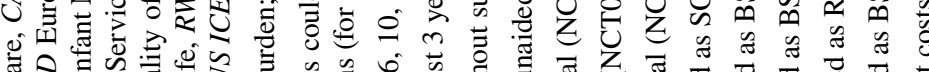

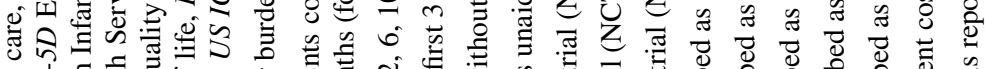

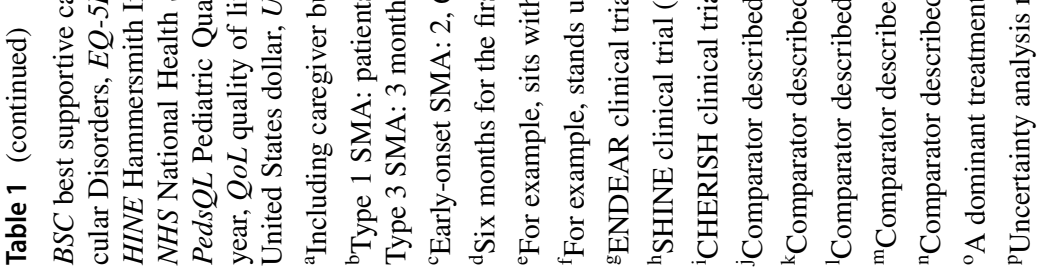


ages, variation in cycle length and the use of different outcome measures to determine clinical efficacy (Table 1). Clinical trial populations included ENDEAR (NCT02193074; infants with SMA aged $\leq 210$ days and with two SMN2 copies) [62], CHERISH (NCT02292537; patients with SMA aged 2-12 years with onset of clinical symptoms after 6 months of age) [63] and SHINE (NCT02594124; patients with SMA who had previously participated in ENDEAR). The population of patients in these trials included patients with Type 1 SMA (ENDEAR and SHINE) [2] and Types 2 and 3 SMA (CHERISH) [63]. Long-term extrapolation beyond clinical trial periods were considered assumptions in the economic evaluations.

Health states included in these models varied between studies for the different types of SMA being modelled (Table 1). The number of health states included in models for Type 1 SMA ranged from five to nine, with the addition of accounting for major clinical interventions such as permanent ventilation, gastrostomy and scoliosis surgery in three of the publications $[55,56,58]$. All the health states included in the models were based on combinations of motor function scales and the achievement of motor milestones (Table 1), and three published economic evaluations incorporated ventilation status [53, 54, 57]. Death (mortality) was included as a health state in the models reported in five publications identified in this SLR [57-61] (Table 1). The health states used were dependent on the scales or motor milestone measures used as endpoints for determining treatment efficacy in the clinical trials used as source data. For example, for early-/infantile-onset SMA, Zuluaga-Sanchez et al. [58] and the HTA submission to NICE [60] (amongst others) used data from the ENDEAR trial [33]. Stabilisation/worsening/improving based on 4-point changes in Children's Hospital of Philadelphia Infant Test of Neuromuscular Disorders (CHOP-INTEND) score were used as health states by Zuluaga-Sanchez et al. [58], while the HTA submission to NICE [60] used health states based on discrete motor milestones as measured by the Hammersmith Infant Neurological Examination, Module 2 (HINE-2). Motor milestones were evaluated using the HINE, which is used to assess Type 1 SMA [64] or World Health Organization (WHO) motor development milestones [65] for later-onset SMA. Motor function scales used were the CHOP-INTEND [66], to evaluate Type 1 SMA, and the Hammersmith Functional Motor Scale-Expanded (HFMSE), to evaluate Type 2 or 3 SMA [67].

\subsubsection{Model Inputs: Healthcare Resource Utilisation and Utilities}

Healthcare resource utilisation, in terms of cost inputs for the models (Table 1), was estimated from a combination of analyses of US health plan claims data and published literature in three of the publications identified in this SLR $[53,57,61]$; from claim data, published literature and expert opinion from the US healthcare perspective [54]; from UK NHS reference costs and general healthcare costs based on published literature and unpublished data from four European countries including the UK [60]; from specified or unspecified published literature $[55,56,59]$; or from an SLR that was reviewed by UK and Swedish clinical experts [58].

All the publications included or considered utility for patients and caregivers and almost all reported/included societal costs (i.e., productivity loss). However, there was an absence of valid patient and caregiver utility data, and the source was not always recorded (Table 1). In the absence of European Quality of Life (EQ-5D) or any preferencebased instrument to estimate utilities in the source data, several economic evaluations used a mapping technique to derive patient utilities as an alternative. Two studies [57, 59] used a mapping technique based on a published [68] or unspecified algorithm. The study by Malone et al. 2019 [57] included utilities mapped from CHERISH to EQ5D-Youth version (EQ-5D-Y), case study review by clinical experts in SMA using EQ-5D-Y and Pediatric Quality of Life Inventory Neuromuscular Module and parent proxyassessed EQ-5D-3 Dimensions utilities. Published sources of utilities for patients with SMA [68-70] were used for the HTA submission to the US ICER Group [61], while other economic evaluations combined unpublished patient utility sources with review by experts in SMA $[57,58]$. In the HTA submission to NICE [60], patient utilities were generated by the manufacturer's clinical advisors. In two economic evaluations, patient utilities were derived from unspecified published literature $[55,56]$ and one study did not report patient utilities [54]. Only three economic evaluations reported caregiver utilities [58,60,61], which were derived from a study of caregiver utilities in Spain [71] or a comparison of health states with the Swedish general population [72].

\subsection{Reported Cost-Effectiveness Results and Uncertainty Analyses}

Although nusinersen was generally found to be associated with improved survival in individuals with SMA, it was found not to be cost effective compared with SOC across all SMA types examined [54-56, 58-61]. The review by NICE [60] reported that nusinersen was in excess of their conventional benchmark of 20,000-30,000 GBP per QALY. The review by CADTH stated that each of the incremental cost-effectiveness ratios obtained in the HTA submission (Types 1, 2 and 3 SMA) were substantially above the standard willingness-to-pay threshold of 300,000 USD per QALY [59]. Similarly, the review by the US ICER Group [61] found that nusinersen exceeded the generally accepted cost-per-QALY threshold for all SMA types. Onasemnogene 
abeparvovec was found to be cost effective compared with chronic nusinersen use in individuals with Type 1 SMA [57], but was not cost effective compared with SOC [61]. The incremental cost-effectiveness ratio range was 203,072 to 31,379 USD per QALY gained for onasemnogene abeparvovec versus nusinersen [61]. Estimates of uncertainty, such as one-way sensitivity analysis, probabilistic sensitivity analysis or scenario analyses, were reported in six of the publications identified in the SLR [54, 57-61]; three studies did not state that estimates of uncertainty were used $[53,55,56]$.

\subsection{Quality Assessment}

Quality assessment was performed for SMA studies presented as full publications $(n=5)$ that were included in this SLR [57-61]. The results of the quality assessment were that these five publications generally provided clear descriptions of objectives, modelling methods and results (ESM Table 6). However, key decisions, such as choice of economic evaluation, model type and choice of variables for sensitivity analysis, were often not adequately justified. Furthermore, while limitations were briefly acknowledged, issues relating to the generalisability of results were rarely addressed. The lowest quality assessment scores were attributed to the HTA submissions to CADTH [59] and NICE [60] (both $\leq 20$ quality considerations); this is likely due to the poor reporting in the available submission documents (less information available) and to an absence of justification for key modelling decisions.

\section{Discussion}

Our SLR of economic modelling studies in SMA identified nine publications covering eight unique studies, including some overlap between the identified published analyses and HTA submissions. In addition, 11 economic evaluations considering the cost effectiveness of treatments for other (non-SMA) neuromuscular disorders (e.g. amyotrophic lateral sclerosis) were identified (refer to ESM) but not analysed further. Given the historic paucity of data on the SMA population, data from these studies may be considered useful for informing future economic evaluations of SMA but were not included in this SLR.

From studies identified in the current SLR, it is evident that different approaches to models exist in the literature. Of the three HTA submissions on SMA, NICE [60] and CADTH [59] used a Markov modelling approach, whereas the US ICER Group [61] used a partitioned survival approach. However, all three HTA submissions developed separate models for infantile-onset and later-onset SMA. Models were based on motor function milestone, but either the milestone definition (which defined the extent of granularity) and/or execution in the models differed between the modelling approaches. Study comparisons across economic evaluations of SMA are challenging because of (i) inconsistences in model structure despite modelling the same disease and using motor milestones as disease health states; (ii) no consensus on which generic instrument should be used to measure utilities for patients (i.e. EQ-5D, EQ5D-Y, Child Health Utility, Health Utility Index Mark 2 or Mark 3); (iii) no consensus on the inclusion of caregiver utilities although deemed important; (iv) no consensus on how resource use should be collected/reported/analysed/included in the model; and (v) no consensus on endpoints such as consistency in measuring motor milestones or measuring progression of the disease (i.e. HINE-2, HFMSE, CHOPINTEND, WHO scores).

Despite inconsistencies in modelling approaches with regards to milestone definitions and milestone inclusion, models using either a Markov or partitioned survival model found that nusinersen was generally associated with increased survival but was not deemed to be cost effective within payer-relevant thresholds when compared with SOC across all SMA types [54-56, 58-61]. Onasemnogene abeparvovec was found to be cost effective when compared with chronic nusinersen treatment in individuals with Type 1 SMA using a Markov model focusing on motor-milestone achievement [57]; however, onasemnogene abeparvovec was not cost effective when compared with SOC [61]. These latter analyses were not carried out using a partitioned survival model.

\subsection{Emerging Economic Evaluations in SMA}

The number of publications relevant to economic evaluations in SMA has increased in the past few years, presumably due to the approval of three DMTs for SMA. Payers may be more willing to accept a higher price for the first available treatment for a rare disease because of the unmet need and lack of competitive treatment options to limit pricing [73]. An outcomes-based managed entry agreement between the manufacturer and payers was established for nusinersen in several countries [74]. Since the SLR was conducted, a summary of the effectiveness and value of treatments for SMA by the US ICER Group [48] and two full-text publications, each with an updated economic model following review by the US ICER Group, have been published. The updated models included nusinersen in patients with infantile-onset SMA [75] and onasemnogene abeparvovec in patients with Type 1 SMA [76]. A recently published SLR assessed six economic evaluations for SMA that included nusinersen versus SOC, nusinersen versus onasemnogene abeparvovec and each against no drug treatment, and nusinersen versus SOC with and without newborn drug screening [77]. Similar to the findings of this SLR, the publication reported 
that nusinersen and onasemnogene abeparvovec were not cost effective as new treatments for SMA management, but the study relied on official prices rather than potential discounted prices [77]. A cost-utility valuation that explored the benefits of available therapies for the UK NHS reported that onasemnogene abeparvovec would not be cost effective compared with SOC or nusinersen; however, a lack of transparency due to a confidential cost arrangement between stakeholders was challenging for a thorough and reliable economic evaluation [78]. Another recently published SLR examined the cost of illness associated with SMA from 14 studies [79]. Recent publications also comprise data suggesting that universal newborn screening for SMA provides improved economic value for payers and patients when nusinersen is available [80]. The two recently published SLRs highlighted the challenges of compiling cross-study comparisons relevant to economic evaluations and cost of illness associated with SMA due to variation in methodological approaches [77, 79]. SLRs have inherent limitations due to variable selection of study criteria [81], which may add further complexity to assessing the economic value of new DMTs for SMA. In contrast to recently published SLRs for SMA [77, 79], we have focussed on evaluating the methodological approaches to economic evaluations in SMA to provide a foundation upon which future payer decisions between innovative treatments for SMA may be more easily compared. To date, no economic evaluation of risdiplam has been published.

\subsection{Implementation of HTA Body Recommendations}

HTA body reviews of the CADTH and NICE HTA submissions $[59,60]$ highlighted limitations in some of the assumptions used in models for both early- and later-onset SMA. From these reviews, HTA body recommendations for future models are that (i) health states should be absolute states relating to the level of functioning at that time rather than states relative to previous functioning [59]; (ii) models with health states based on motor function milestones only should also capture the impact of other outcomes such as respiratory function and the requirement for ventilation [60]; (iii) utility values should be derived from published analyses and direct methods, instead of mapping [59]; and (iv) costs associated with the management of SMA should be reported in an age- and motor milestone-dependent context [60]. Some of the changes between the reviewed economic evaluation models may have been implemented following feedback from HTA body review groups. For example, entry of patients into the model in the baseline health state was used in the HTA submission to CADTH for nusinersen [59], but the review by the CADTH HTA body recommended that health states should not relate to previous functioning.
Health state at baseline was not incorporated in the HTA submission to NICE [60]. The inclusion of additional health states such as respiratory function and the requirement for ventilation may also have helped these models to capture the impact of SMA more accurately.

\subsection{Long-Term Modelling Implications}

Findings from the six published economic evaluations must be interpreted in the context of individual study caveats. Limitations of the five studies on which the publications were based often related to the absence of long-term effectiveness and safety data $[54,55,58]$, the restricted generalisability of results [57] and a requirement for assumptions concerning survival, utilities and whether the motor function milestone was sustained over a lifetime [54]. Economic evaluations would benefit from long-term follow-up of clinical trial participants to fully capture the benefits, such as QALYs or motor function improvement, associated with SMA treatment. Compilation of such treatment benefits should be included in registries to better inform future model updates. Indeed, almost half of the studies identified in this SLR were conference abstracts; limited reporting renders robust quality assessment of economic evaluation studies more difficult. As additional economic evaluations are carried out with longer-term data, conclusions may change. For example, when compared with individuals with Type 1 SMA, individuals with Types 2 and 3 SMA have a longer latency between clinical onset and significant disease progression, which provides more time for treatments to offer beneficial effects [82]. Therefore, ICER-per-QALY values may show increased variation in Types 2 and 3 SMA, compared with Type 1 SMA. Other challenges for economic evaluations in SMA that could be addressed in the future include lack of consideration for patient preference regarding treatment benefit versus risk, potential for improvement in particular clinical domains (e.g. motor function, respiratory function) and treatment attributes such as route of administration and age indications $[83,84]$.

\subsection{Consistency in Appropriate Motor Function Assessment}

There is no uniform approach or standardised scale to measure outcomes for all types of SMA, from childhood through to adulthood. This has proven to be a barrier for understanding disease progression and for comparing results from different studies [14, 22, 85]. The publications identified in this SLR have shown some consistency with both HINE-2 and WHO motor milestones used for early- and later-onset SMA, respectively, and the CHOP-INTEND and HFMSE scales to define worsening/improvement in some health states in early- and later-onset SMA, respectively. HFMSE 
is commonly used to assess motor function ability in lateronset SMA but it has been shown that this scale is more appropriate to assess stronger non-ambulant patients and may be less sensitive to detect change in weaker patients [86]. Inclusion of additional scales more able to capture change in weaker patients, or a combination of scales, may be needed to improve scale reliability across patient cohorts [87-89] to ensure that clinical efficacy is fully captured. It would be helpful if a consensus on the method of measuring motor function used in modelling could be reached that reflects the newer recommended terms for SMA, based on descriptive terms of the motor milestones achieved by individuals, in contrast to the traditional 'types'. As real-world evidence is valuable for decision making, in particular for a rare disease such as SMA, consistency in clinical trial and natural history data collection by registries will also prove to be important.

\subsection{Consensus in Modelling Structure and SMA Health State Classification}

To improve consistency in cost-effectiveness modelling in SMA, it may be useful to examine the approach used in other diseases to unify models. Project HERCULES is a collaborative project between Duchenne UK and eight pharmaceutical companies to develop a cost-effectiveness model for DMD in which health states are informed by clinicians, patients and caregivers [90]. In addition to model flexibility to incorporate different input parameters, such as interventions and comparators, patient populations and treatment effects, Project HERCULES incorporates expertise from manufacturers, decision makers and clinical experts to develop a model [90]. In the past, key opinion leaders, modellers and economists liaised to develop the CORE Diabetes Model for diabetes mellitus [91], which later became a global, internetbased, interactive computer model that permits simulations of different populations of patients with diabetes in realistic clinical settings. It would be beneficial for stakeholders associated with SMA to consider a bespoke approach to economic modelling of SMA through the adoption of successful elements of approaches used elsewhere.

An important consideration for future economic evaluations involves a change in the way many experts are classifying SMA (the traditional categorisation of types is based on the age of onset and highest motor milestone achieved). Increased survival and improvement of motor function have been a direct result of both DMTs and enhanced medical care and are leading to the emergence of new phenotypes [2, 82, $92,93]$. For example, DMT use has resulted in patients with Type 1 SMA who can sit and patients with Type 2 SMA who can walk [92], which are milestones that are never achieved in natural history. Recommended terms for re-classification of SMA include 'non-sitters', 'sitters' and 'walkers', which better reflect current motor function and associated dependence on caregivers [2]. This approach to classification allows for both attainment of milestones following treatment that are never normally achieved in natural history, and also for the loss of motor function that may occur in a degenerative disease (e.g. a patient initially classified as having Type 2 SMA may become a 'non-sitter' due to disease progression). An abstract and associated poster presented by Paracha et al. at ISPOR 2020 [94] highlighted further refinement in economic models proposed for SMA. In the study by Paracha et al., the functional milestones were defined using the HINE-2 and 32-item Motor Function Measure scales for infantile-onset (Type 1) SMA and later-onset (Types 2 and 3) SMA, respectively. Moreover, the proposed Markov model for Type 1 SMA included four motor function milestones ('not sitting', 'sitting', 'standing' and 'walking') to reflect disease severity together with 'permanent ventilation' and 'death' health states. Standing was added as an intermediate health state because reliance on a caregiver may diminish or may not be required in this state, which is an important consideration both for informal costs and quality of life. The proposed Types 2/3 SMA Markov model was identical to the Type 1 SMA model, except for the removal of 'not sitting' and 'permanent ventilation' health states. Individuals could transition between these defined motor function milestones and each of the health states included a 'with or without' sub-health state to account for potential differences in quality of life and costs, which has not been included in previous models. A recently published economic model using the health states 'permanent ventilation', 'not sitting', 'walking' and 'death' assessed nusinersen treatment versus SOC for patients with infantile-onset SMA in the US [75]. This study found that nusinersen treatment achieved QALYs and life-years (LYs) (3.24 and 7.64, respectively) that were higher than SOC (QALY, 0.46; LYs, 2.40) [75]. Therefore, the application of revised SMA classification, in addition to increased understanding of the prevalence of SMA, may impact assessments of economic modelling of SMA in the future.

\subsection{Measuring Change That is Meaningful for Patients in Economic Evaluations}

Although payers are primarily interested in generic preference-based measures to compare the added value of interventions across diseases [95], patient-reported outcomes are becoming increasingly important in decision making by payers. Motor and respiratory function were the primary outcome measures assessed in the studies identified in this SLR. However, meaningful changes to patients with SMA, such as fine finger movements or the ability to turn one's head, may not be captured by current scales for clinical trial endpoints [96]. Patients, caregivers and clinicians 
have also highlighted that outcome measures should assess aspects of SMA such as the ability to perform daily activities, respiratory function, swallowing, fatigue and endurance [97]. Indeed, from a survey of patients with Type 2/3 SMA, respiratory-related symptoms were commonly selected as having significant impact on life [98]. The models presented by Paracha et al. at ISPOR 2020 allowed for the application of utility decrements to disease-related impacts of interest such as respiratory support and orthopaedic conditions [94]. Guidance for clinical outcome assessments increasingly emphasises the inclusion of meaningful change at an individual patient level [99], and so this may be more routinely addressed in future economic evaluations in SMA.

\section{Conclusions}

This SLR provides a comprehensive repository of the methodological approaches used in currently available economic evaluations relevant to patients with SMA. Importantly, limitations of the identified studies highlight several weaknesses, such as lack of consensus on modelling the disease (model structure) and data defining model health states. In addition, several data gaps exist, including a lack of long-term efficacy and safety data from clinical trials, and an absence of consensus on which generic preference measure should be used to estimate utilities in both infantile-onset and lateronset SMA. The application of traditional cost-effectiveness thresholds means that orphan drugs for rare and ultra-rare conditions rarely meet cost-effectiveness thresholds [49]. The absence of robust data inputs also highlights the importance of global, regional and/or local data collection platforms and disease registry networks.

Long-term data generated by clinical trials and improved data collection in registries will further inform future economic evaluation model updates and help to fully capture the long-term benefits associated with current and emerging SMA treatments such as QALYs or motor function among individuals with early- and later-onset SMA. Future economic evaluations should incorporate the review group critiques of previous HTA submissions relating to data inputs and approaches to modelling, and should include patient data reflective of the SMA population being modelled. Collaboration between pharmaceutical companies and HTA decisions makers should also be considered based on Project HERCULES for DMD [90] and CORE Diabetes [91].

Supplementary Information The online version contains supplementary material available at https://doi.org/10.1007/s40273-021-01095-6.

Acknowledgements The authors thank Rosalind Carney, DPhil, of MediTech Media Ltd for providing medical writing support, which was funded by F. Hoffmann-La Roche Ltd, Basel, Switzerland in accordance with Good Publication Practice (GPP3) guidelines (http:// www.ismpp.org/gpp3).

\section{Declarations}

Funding This study was funded by F. Hoffmann-La Roche Ltd, Basel, Switzerland.

Disclosure statement This article is published in a special edition journal supplement wholly funded by F. Hoffmann-La Roche Ltd.

Conflict of interest During the preparation of this manuscript, C. Simone Sutherland was employed by F. Hoffmann-La Roche and owns stocks in Roche. During the preparation of this manuscript, Noman Paracha was employed by F. Hoffmann-La Roche and owns stocks in Roche. Pollyanna Hudson's and Stephen Mitchell's employer, Mtech Access, was commissioned by Roche, and therefore received a consulting fee to conduct the systematic review presented in the manuscript.

Ethics approval Not applicable.

Consent to participate Not applicable.

Consent for publication Not applicable.

Availability of data and material Not applicable.

Code availability Not applicable.

Author contributions NP and CSS conceptualised the study and all authors contributed to the study design. PH and SM conducted the literature search, data extraction, initial summary of results and quality assessment. All authors contributed to data interpretation and development of the manuscript, including figures, tables and online resource materials. All authors approved the final version of the manuscript.

Open Access This article is licensed under a Creative Commons Attribution-NonCommercial 4.0 International License, which permits any non-commercial use, sharing, adaptation, distribution and reproduction in any medium or format, as long as you give appropriate credit to the original author(s) and the source, provide a link to the Creative Commons licence, and indicate if changes were made. The images or other third party material in this article are included in the article's Creative Commons licence, unless indicated otherwise in a credit line to the material. If material is not included in the article's Creative Commons licence and your intended use is not permitted by statutory regulation or exceeds the permitted use, you will need to obtain permission directly from the copyright holder. To view a copy of this licence, visit http://creativecommons.org/licenses/by-nc/4.0/.

\section{References}

1. Crawford TO, Pardo CA. The neurobiology of childhood spinal muscular atrophy. Neurobiol Dis. 1996;3(2):97-110. https://doi. org/10.1006/nbdi.1996.0010.

2. Wirth B, Karakaya M, Kye MJ, Mendoza-Ferreira N. Twenty-five years of spinal muscular atrophy research: from phenotype to genotype to therapy, and what comes next. Annu Rev Genomics Hum Genet. 2020;21:231-61. https://doi.org/10.1146/annur ev-genom-102319-103602. 
3. Wirth B. An update of the mutation spectrum of the survival motor neuron gene (SMN1) in autosomal recessive spinal muscular atrophy (SMA). Hum Mutat. 2000;15(3):228-37. https:// doi.org/10.1002/(SICI)1098-1004(200003)15:3\%3c228::AIDHUMU3\%3e3.0.CO;2-9.

4. Kolb SJ, Kissel JT. Spinal muscular atrophy. Neurol Clin. 2015;33(4):831-46. https://doi.org/10.1016/j.ncl.2015.07.004.

5. Lorson CL, Hahnen E, Androphy EJ, Wirth B. A single nucleotide in the SMN gene regulates splicing and is responsible for spinal muscular atrophy. Proc Natl Acad Sci USA. 1999;96(11):6307-11. https://doi.org/10.1073/pnas.96.11.6307.

6. Crawford TO, Paushkin SV, Kobayashi DT, Forrest SJ, Joyce CL, Finkel RS, et al. Evaluation of SMN protein, transcript, and copy number in the biomarkers for spinal muscular atrophy (BforSMA) clinical study. PLoS ONE. 2012;7(4): e33572. https://doi.org/10.1371/journal.pone.0033572.

7. Feldkotter M, Schwarzer V, Wirth R, Wienker TF, Wirth B. Quantitative analyses of SMN1 and SMN2 based on real-time lightCycler PCR: fast and highly reliable carrier testing and prediction of severity of spinal muscular atrophy. Am J Hum Genet. 2002;70(2):358-68. https://doi.org/10.1086/338627.

8. Saffari A, Kolker S, Hoffmann GF, Weiler M, Ziegler A. Novel challenges in spinal muscular atrophy - how to screen and whom to treat? Ann Clin Transl Neurol. 2019;6(1):197-205. https://doi. org/10.1002/acn3.689.

9. Dubowitz V. Very severe spinal muscular atrophy (SMA type 0 ): an expanding clinical phenotype. Eur J Paediatr Neurol. 1999;3(2):49-51. https://doi.org/10.1053/ejpn.1999.0181.

10. Munsat TL. International SMA Collaboration. Neuromuscul Disord. 1991;1(2):81. https://doi.org/10.1016/0960-8966(91) 90052-T.

11. Munsat TL, Davies KE. International SMA Consortium meeting (26-28 June 1992, Bonn, Germany). Neuromuscul Disord. 1992;2(5-6):423-8. https://doi.org/10.1016/s0960-8966(06) 80015-5.

12. Talbot K, Tizzano EF. The clinical landscape for SMA in a new therapeutic era. Gene Ther. 2017;24(9):529-33. https://doi.org/ 10.1038/gt.2017.52.

13. Belter L, Cruz R, Jarecki J. Quality of life data for individuals affected by spinal muscular atrophy: a baseline dataset from the Cure SMA Community Update Survey. Orphanet J Rare Dis. 2020;15:217.

14. Mercuri E, Bertini E, Iannaccone ST. Childhood spinal muscular atrophy: controversies and challenges. Lancet Neurol. 2012;11(5):443-52. https://doi.org/10.1016/S1474-4422(12) 70061-3.

15. Mercuri E, Finkel RS, Muntoni F, Wirth B, Montes J, Main M, et al. Diagnosis and management of spinal muscular atrophy: part 1: recommendations for diagnosis, rehabilitation, orthopedic and nutritional care. Neuromuscul Disord. 2018;28(2):103-15. https://doi.org/10.1016/j.nmd.2017.11.005.

16. Wan HWY, Carey KA, D'Silva A, Vucic S, Kiernan MC, Kasparian NA, et al. Health, wellbeing and lived experiences of adults with SMA: a scoping systematic review. Orphanet J Rare Dis. 2020;15(1):70. https://doi.org/10.1186/s13023-020-1339-3.

17. Zerres K, Rudnik-Schoneborn S. Natural history in proximal spinal muscular atrophy. Clinical analysis of 445 patients and suggestions for a modification of existing classifications. Arch Neurol. 1995;52(5):518-23. https://doi.org/10.1001/archneur. 1995.00540290108025 .

18. Thomas NH, Dubowitz V. The natural history of type I (severe) spinal muscular atrophy. Neuromuscul Disord. 1994;4(5-6):497502. https://doi.org/10.1016/0960-8966(94)90090-6.

19. Finkel RS, McDermott MP, Kaufmann P, Darras BT, Chung WK, Sproule DM, et al. Observational study of spinal muscular atrophy type I and implications for clinical trials. Neurology.
2014;83(9):810-7. https://doi.org/10.1212/WNL.0000000000 000741 .

20. D'Amico A, Mercuri E, Tiziano FD, Bertini E. Spinal muscular atrophy. Orphanet J Rare Dis. 2011;6:71. https://doi.org/10.1186/ 1750-1172-6-71.

21. Wang CH, Finkel RS, Bertini ES, Schroth M, Simonds A, Wong $\mathrm{B}$, et al. Consensus statement for standard of care in spinal muscular atrophy. J Child Neurol. 2007;22(8):1027-49. https://doi. org/10.1177/0883073807305788.

22. Schorling DC, Pechmann A, Kirschner J. Advances in treatment of spinal muscular atrophy - new phenotypes, new challenges, new implications for care. J Neuromuscul Dis. 2020;7(1):1-13. https://doi.org/10.3233/JND-190424.

23. Finkel RS, Mercuri E, Meyer OH, Simonds AK, Schroth MK, Graham RJ, et al. Diagnosis and management of spinal muscular atrophy: part 2: pulmonary and acute care; medications, supplements and immunizations; other organ systems; and ethics. Neuromuscul Disord. 2018;28(3):197-207. https://doi.org/ 10.1016/j.nmd.2017.11.004.

24. Food and Drug Administration. SPINRAZA ${ }^{\circledR}$ (nusinersen) [package insert]. Cambridge: Biogen Inc.; 2016.

25. European Medicines Agency. Spinraza. 2017. https://www. ema.europa.eu/en/medicines/human/EPAR/spinraza. Accessed 06 Nov 2020.

26. Food and Drug Administration. ZOLGENSMA ${ }^{\circledR}$ (onasemnogene abeparvovec-xioi) [package insert]. Bannockburn: AveXis Inc.; 2019.

27. European Medicines Agency. Zolgensma. 2020. https:// www.ema.europa.eu/en/medicines/human/EPAR/zolgensma. Accessed 06 Nov 2020.

28. Food and Drug Administration. EVRYSDI ${ }^{\mathrm{TM}}$ (risdiplam) [package insert]. South San Francisco: Genentech Inc.; 2020.

29. European Medicines Agency. Risdiplam. 2021. https://www. ema.europa.eu/en/medicines/human/EPAR/evrysdi. Accessed 05 May 2021.

30. Rigo F, Hua Y, Krainer AR, Bennett CF. Antisense-based therapy for the treatment of spinal muscular atrophy. J Cell Biol. 2012;199(1):21-5. https://doi.org/10.1083/jcb.201207087.

31. Mendell JR, Al-Zaidy S, Shell R, Arnold WD, Rodino-Klapac LR, Prior TW, et al. Single-dose gene-replacement therapy for spinal muscular atrophy. N Engl J Med. 2017;377(18):171322. https://doi.org/10.1056/NEJMoa1706198.

32. Ratni H, Ebeling M, Baird J, Bendels S, Bylund J, Chen KS, et al. Discovery of risdiplam, a selective survival of motor neuron-2 (SMN2) gene splicing modifier for the treatment of spinal muscular atrophy (SMA). J Med Chem. 2018;61(15):650117. https://doi.org/10.1021/acs.jmedchem.8b00741.

33. Finkel RS, Chiriboga CA, Vajsar J, Day JW, Montes J, De Vivo DC, et al. Treatment of infantile-onset spinal muscular atrophy with nusinersen: a phase 2, open-label, dose-escalation study. Lancet. 2016;388(10063):3017-26. https://doi.org/10.1016/ S0140-6736(16)31408-8.

34. Al-Zaidy SA, Kolb SJ, Lowes L, Alfano LN, Shell R, Church $\mathrm{KR}$, et al. AVXS-101 (onasemnogene abeparvovec) for SMA1: comparative study with a prospective natural history cohort. J Neuromuscul Dis. 2019;6(3):307-17. https://doi.org/10.3233/ JND-190403.

35. De Vivo DC, Bertini E, Swoboda KJ, Hwu WL, Crawford TO, Finkel RS, et al. Nusinersen initiated in infants during the presymptomatic stage of spinal muscular atrophy: interim efficacy and safety results from the phase 2 NURTURE study. Neuromuscul Disord. 2019;29(11):842-56. https://doi.org/10. 1016/j.nmd.2019.09.007.

36. Darras BT, Chiriboga CA, Iannaccone ST, Swoboda KJ, Montes J, Mignon L, et al. Nusinersen in later-onset spinal muscular atrophy: long-term results from the phase $1 / 2$ studies. 
Neurology. 2019;92(21):e2492-506. https://doi.org/10.1212/ WNL.0000000000007527.

37. Lowes LP, Alfano LN, Arnold WD, Shell R, Prior TW, McColly M, et al. Impact of age and motor function in a phase $1 / 2 \mathrm{~A}$ study of infants with SMA type 1 receiving single-dose gene replacement therapy. Pediatr Neurol. 2019;98:39-45. https://doi.org/10.1016/j.pediatrneurol.2019.05.005.

38. Montes J, Dunaway Young S, Mazzone ES, Pasternak A, Glanzman AM, Finkel RS, et al. Nusinersen improves walking distance and reduces fatigue in later-onset spinal muscular atrophy. Muscle Nerve. 2019;60(4):409-14. https://doi.org/10. 1002/mus.26633.

39. Baranello G, Darras BT, Day JW, Deconinck N, Klein A, Masson $\mathrm{R}$, et al. Risdiplam in type 1 spinal muscular atrophy. $\mathrm{N}$ Engl J Med. 2021;384(10):915-23. https://doi.org/10.1056/ NEJMoa2009965.

40. Darras BT, Masson R, Mazurkiewicz-Bełdińska M, Rose K, Xiong H, Zanoteli E. Risdiplam-treated infants with type 1 spinal muscular atrophy versus historical controls. N Engl J Med. 2021;385(5):427-35. https://doi.org/10.1056/NEJMo a2102047.

41. Wirth B. Spinal muscular atrophy: in the challenge lies a solution. Trends Neurosci. 2021;44(4):306-22. https://doi.org/10. 1016/j.tins.2020.11.009.

42. Farrar MA, Kiernan MC. Spinal muscular atrophy - the dawning of a new era. Nat Rev Neurol. 2020;16(11):593-4. https://doi. org/10.1038/s41582-020-00410-7.

43. van der Ploeg AT. The dilemma of two innovative therapies for spinal muscular atrophy. N Engl J Med. 2017;377(18):1786-7. https://doi.org/10.1056/NEJMe1712106.

44. Mattingly TJ 2nd, Simoni-Wastila L. Patient-centered drug approval: the role of patient advocacy in the drug approval process. J Manag Care Spec Pharm. 2017;23(10):1078-82. https:// doi.org/10.18553/jmcp.2017.23.10.1078.

45. Facey K, Granados A, Guyatt G, Kent A, Shah N, van der Wilt GJ, et al. Generating health technology assessment evidence for rare diseases. Int J Technol Assess Health Care. 2014;30(4):41622. https://doi.org/10.1017/S0266462314000464.

46. Neumann PJ, Goldie SJ, Weinstein MC. Preference-based measures in economic evaluation in health care. Annu Rev Public Health. 2000;21:587-611. https://doi.org/10.1146/annurev.publh ealth.21.1.587.

47. Nestler-Parr S, Korchagina D, Toumi M, Pashos CL, Blanchette $\mathrm{C}$, Molsen E, et al. Challenges in research and health technology assessment of rare disease technologies: report of the ISPOR Rare Disease Special Interest Group. Value Health. 2018;21(5):493-500. https://doi.org/10.1016/j.jval.2018.03.004.

48. Pearson SD, Thokala P, Stevenson M, Rind D. The effectiveness and value of treatments for spinal muscular atrophy. J Manag Care Spec Pharm. 2019;25(12):1300-6. https://doi.org/10.18553/ jmcp.2019.25.12.1300.

49. ICER. Assessing the effectiveness and value of drugs for rare conditions. 2017. https://icer.org/wp-content/uploads/2020/10/ ICER_Assessing-the-Value-of-Drugs-for-Rare-Conditions_ 051017-1.pdf. Accessed 6 Nov 2019.

50. Page MJ, McKenzie JE, Bossuyt PM, Boutron I, Hoffmann TC, Mulrow CD, et al. The PRISMA 2020 statement: an updated guideline for reporting systematic reviews. BMJ. 2021;372: n71. https://doi.org/10.1136/bmj.n71.

51. Richardson WS, Wilson MC, Nishikawa J, Hayward RS. The well-built clinical question: a key to evidence-based decisions. ACP J Club. 1995;123(3):A12-3.

52. Drummond MF, Jefferson TO. Guidelines for authors and peer reviewers of economic submissions to the BMJ. The BMJ Economic Evaluation Working Party. BMJ. 1996;313(7052):275-83. https://doi.org/10.1136/bmj.313.7052.275.
53. Malone D, Dean R, Miller B, Arjunji R, Feltner DE, Sproule DM, et al. ND2 cost-utility analysis of single dose gene-replacement therapy for spinal muscular atrophy Type 1 compared to chronic nusinersen treatment. Value Health. 2019;22:S42-3. https://doi. org/10.1016/j.jval.2019.04.060.

54. Thokala P, Stevenson M, Kumar VM, Ren S, Chapman R, Ellis A, et al. PRO15 cost-effectiveness of nusinersen and onasemnogene abeparvovec for infantile-onset spinal muscular atrophy (Type I SMA) in the US. Value Health. 2019;22:S337-8. https:// doi.org/10.1016/j.jval.2019.04.1648.

55. Zuluaga-Sanchez S, Purser M, Mader G, Gould IG, Knight C, Johnson NB, et al. PRO14 improved quality of life and life-years in patients with infantile-onset SMA following treatment with nusinersen. Value Health. 2019;22:S337. https://doi.org/10. 1016/j.jval.2019.04.1647.

56. Zuluaga-Sanchez S, Purser M, Mader G, Gould IG, Knight C, Patel M, et al. PRO16 improved quality of life for patients and caregivers among patients with later-onset sma following treatment with nusinersen. Value Health. 2019;22:S338. https://doi. org/10.1016/j.jval.2019.04.1649.

57. Malone DC, Dean R, Arjunji R, Jensen I, Cyr P, Miller B, et al. Cost-effectiveness analysis of using onasemnogene abeparvocec (AVXS-101) in spinal muscular atrophy type 1 patients. J Mark Access Health Policy. 2019;7(1):1601484. https://doi. org/10.1080/20016689.2019.1601484.

58. Zuluaga-Sanchez S, Teynor M, Knight C, Thompson R, Lundqvist T, Ekelund M, et al. Cost effectiveness of nusinersen in the treatment of patients with infantile-onset and later-onset spinal muscular atrophy in Sweden. Pharmacoeconomics. 2019;37(6):845-65. https://doi.org/10.1007/ s40273-019-00769-6.

59. CADTH. Pharmacoeconomic review report nusinersen (Spinraza). 2018. https://www.cadth.ca/sites/default/files/cdr/pharm acoeconomic/SR0525_Spinraza_PE_Report.pdf. Accessed 06 Nov 2019.

60. NICE. TA588 Nusinersen for treating spinal muscular atrophy. 2018. https://www.nice.org.uk/guidance/ta588/documents/ committee-papers. Accessed 06 Nov 2019.

61. ICER. Spinraza ${ }^{\circledR}$ and Zolgensma ${ }^{\circledR}$ for spinal muscular atrophy: effectiveness and value. 2019. https://icer-review.org/wp-conte nt/uploads/2018/07/ICER_SMA_Final_Evidence_Report_ 040319.pdf. Accessed 06 Nov 2019.

62. Finkel RS, Mercuri E, Darras BT, Connolly AM, Kuntz NL, Kirschner J, et al. Nusinersen versus sham control in infantile-onset spinal muscular atrophy. $\mathrm{N}$ Engl J Med. 2017;377(18):1723-32. https://doi.org/10.1056/NEJMoa1702 752.

63. Mercuri E, Darras BT, Chiriboga CA, Day JW, Campbell C, Connolly AM, et al. Nusinersen versus sham control in later-onset spinal muscular atrophy. N Engl J Med. 2018;378(7):625-35. https://doi.org/10.1056/NEJMoa1710 504.

64. Haataja L, Mercuri E, Regev R, Cowan F, Rutherford M, Dubowitz V, et al. Optimality score for the neurologic examination of the infant at 12 and 18 months of age. J Pediatr. 1999;135(2 Pt 1):153-61. https://doi.org/10.1016/s00223476(99)70016-8.

65. Group WHOMGRS. WHO Motor Development Study: windows of achievement for six gross motor development milestones. Acta Paediatr Suppl. 2006;450:86-95. https://doi.org/10.1111/j.16512227.2006.tb02379.x.

66. Glanzman AM, Mazzone E, Main M, Pelliccioni M, Wood J, Swoboda KJ, et al. The Children's Hospital of Philadelphia Infant Test of Neuromuscular Disorders (CHOP INTEND): test development and reliability. Neuromuscul Disord. 2010;20(3):155-61. https://doi.org/10.1016/j.nmd.2009.11.014. 
67. O'Hagen JM, Glanzman AM, McDermott MP, Ryan PA, Flickinger J, Quigley J, et al. An expanded version of the Hammersmith Functional Motor Scale for SMA II and III patients. Neuromuscul Disord. 2007;17(9-10):693-7. https://doi.org/10.1016/j. nmd.2007.05.009.

68. Thompson R, Vaidya S, Teynor M. The utility of different approachs to developing health utilities data in childhood rare diseases - a case study in spinal muscular atrophy (SMA). Value Health. 2017;20(9):A725-6. https://doi.org/10.1016/j.jval.2017. 08.1962 .

69. Sullivan PW, Ghushchyan V. Preference-based EQ-5D index scores for chronic conditions in the United States. Med Decis Mak. 2006;26(4):410-20. https://doi.org/10.1177/0272989X06 290495.

70. Tappenden P, Hamilton J, Kaltenthaler E, Hock E, Rawdin A, Mukuria C, et al. Nusinersen for treating spinal muscular atrophy: a single technology appraisal. In: School of health and related research (ScHARR). 2018. https://www.nice.org.uk/ guidance/ta588/documents/appraisal-consultation-document. Accessed 6 Nov 2019.

71. Bastida JL and Research Team. Social economic costs and health-related quality of life in patients with spinal muscular atrophy in Europe. University of Castilla-La Mancha (Ciudad Real, Spain); Toledo, Spain; 2016.

72. Burstrom K, Johannesson M, Diderichsen F. Swedish population health-related quality of life results using the EQ-5D. Qual Life Res. 2001;10(7):621-35. https://doi.org/10.1023/a:1013171831 202.

73. Lucas F. Improving market access to rare disease therapies: a worldwide perspective with recommendations to the industry. Medicine Access @ Point of Care. 2018;2:2399202618810121. https://doi.org/10.1177/2399202618810121

74. Facey KM, Espin J, Kent E, Link A, Nicod E, O’Leary A, et al. Implementing outcomes-based managed entry agreements for rare disease treatments: nusinersen and tisagenlecleucel. Pharmacoeconomics. 2021;39(9):1021-44. https://doi.org/10.1007/ s40273-021-01050-5.

75. Thokala P, Stevenson M, Kumar VM, Ren S, Ellis AG, Chapman RH. Cost effectiveness of nusinersen for patients with infantileonset spinal muscular atrophy in US. Cost Eff Resour Alloc. 2020;18:41. https://doi.org/10.1186/s12962-020-00234-8.

76. Dean R, Jensen I, Cyr P, Miller B, Maru B, Sproule DM, et al. An updated cost-utility model for onasemnogene abeparvovec $($ Zolgensma(R)) in spinal muscular atrophy type 1 patients and comparison with evaluation by the Institute for Clinical and Effectiveness Review (ICER). J Mark Access Health Policy. 2021;9(1):1889841. https://doi.org/10.1080/20016689.2021. 1889841.

77. Dangouloff T, Botty C, Beaudart C, Servais L, Hiligsmann M. Systematic literature review of the economic burden of spinal muscular atrophy and economic evaluations of treatments. Orphanet J Rare Dis. 2021;16(1):47. https://doi.org/10.1186/ s13023-021-01695-7.

78. Connock M, Andronis L, Auguste P, Dussart C, Armoiry X. Will the US\$5 million onasemnogene abeparvosec treatment for spinal muscular atrophy represent "value for money" for the NHS? A rapid inquiry into suggestions that it may be cost-effective. Expert Opin Biol Ther. 2020;20(7):823-7. https://doi.org/10. 1080/14712598.2020.1772747.

79. Landfeldt E, Pechmann A, McMillan HJ, Lochmuller H, Sejersen T. Costs of illness of spinal muscular atrophy: a systematic review. Appl Health Econ Health Policy. 2021. https://doi.org/ 10.1007/s40258-020-00624-2.

80. Jalali A, Rothwell E, Botkin JR, Anderson RA, Butterfield RJ, Nelson RE. Cost-effectiveness of nusinersen and universal newborn screening for spinal muscular atrophy. J Pediatr. 2020;227(274-80): e2. https://doi.org/10.1016/j.jpeds.2020. 07.033 .

81. Gopalakrishnan S, Ganeshkumar P. Systematic reviews and metaanalysis: understanding the best evidence in primary healthcare. $\mathrm{J}$ Family Med Prim Care. 2013;2(1):9-14. https://doi.org/10.4103/ 2249-4863.109934.

82. Tizzano EF, Finkel RS. Spinal muscular atrophy: a changing phenotype beyond the clinical trials. Neuromuscul Disord. 2017;27(10):883-9. https://doi.org/10.1016/j.nmd.2017.05.011.

83. Lo SH, Paracha N, Ali S, Lloyd A. PRO92 estimating disutilities in spinal muscular atrophy using a stated preference survey: a UK general public study. Value Health. 2020;23:S345. https:// doi.org/10.1016/j.jval.2020.04.1313.

84. Monnette A, Chen E, Hong D, Bazzano A, Dixon S, Arnold $\mathrm{WD}$, et al. Treatment preference among patients with spinal muscular atrophy (SMA): a discrete choice experiment. Orphanet J Rare Dis. 2021;16(1):36. https://doi.org/10.1186/ s13023-020-01667-3.

85. Montes J, McDermott MP, Mirek E, Mazzone ES, Main M, Glanzman AM, et al. Ambulatory function in spinal muscular atrophy: age-related patterns of progression. PLoS ONE. 2018;13(6): e0199657. https://doi.org/10.1371/journal.pone.0199657.

86. Wijngaarde CA, Stam M, Otto LAM, Bartels B, Asselman FL, van Eijk RPA, et al. Muscle strength and motor function in adolescents and adults with spinal muscular atrophy. Neurology. 2020;95(14):e1988-98. https://doi.org/10.1212/WNL.00000 00000010540

87. Cano SJ, Mayhew A, Glanzman AM, Krosschell KJ, Swoboda $\mathrm{KJ}$, Main M, et al. Rasch analysis of clinical outcome measures in spinal muscular atrophy. Muscle Nerve. 2014;49(3):422-30. https://doi.org/10.1002/mus.23937.

88. Mazzone E, De Sanctis R, Fanelli L, Bianco F, Main M, van den Hauwe M, et al. Hammersmith Functional Motor Scale and Motor Function Measure-20 in non ambulant SMA patients. Neuromuscul Disord. 2014;24(4):347-52. https://doi.org/10. 1016/j.nmd.2014.01.003.

89. Rouault F, Christie-Brown V, Broekgaarden R, Gusset N, Henderson D, Marczuk P, et al. Disease impact on general wellbeing and therapeutic expectations of European Type II and Type III spinal muscular atrophy patients. Neuromuscul Disord. 2017;27(5):428-38. https://doi.org/10.1016/j.nmd.2017.01.018.

90. Woodcock F, Mumby-Croft J, Ghosh S, Chandler F, Godfrey J, Crossley E. PRO16 project Hercules: a case study in developing a multi-company, flexible cost-effectiveness model in a rare disease. Value Health. 2019;22:S843. https://doi.org/10.1016/j. jval.2019.09.2347.

91. Palmer AJ, Roze S, Valentine WJ, Minshall ME, Foos V, Lurati FM, et al. The CORE Diabetes Model: projecting long-term clinical outcomes, costs and cost-effectiveness of interventions in diabetes mellitus (types 1 and 2) to support clinical and reimbursement decision-making. Curr Med Res Opin. 2004;20(Suppl 1):S5-26. https://doi.org/10.1185/030079904X1980.

92. Sansone VA, Walter MC, Attarian S, Delstanche S, Mercuri E, Lochmuller $\mathrm{H}$, et al. Measuring outcomes in adults with spinal muscular atrophy - challenges and future directions - meeting report. J Neuromuscul Dis. 2020;7(4):523-34. https://doi.org/ 10.3233/JND-200534.

93. Mercuri E, Pera MC, Scoto M, Finkel R, Muntoni F. Spinal muscular atrophy - insights and challenges in the treatment era. Nat Rev Neurol. 2020. https://doi.org/10.1038/s41582-020-00413-4.

94. Paracha N, Gorni K, Hudson P. PRO62 spinal muscular atrophy: development of natural history models for disease subtypes. Value Health. 2020;23:S339. https://doi.org/10.1016/j.jval.2020. 04.1284. 
95. Brazier J, Ratcliffe J, Salomon J, Tsuchiya A. Measuring and valuing health benefits for economic evaluation. OUP Catalogue. 2016.

96. Pierzchlewicz K, Kepa I, Podogrodzki J, Kotulska K. Spinal muscular atrophy: the use of functional motor scales in the era of disease-modifying treatment. Child Neurol Open. 2021;8:2329048X211008725. https://doi.org/10.1177/23290 48X211008725.

97. McGraw S, Qian Y, Henne J, Jarecki J, Hobby K, Yeh WS. A qualitative study of perceptions of meaningful change in spinal muscular atrophy. BMC Neurol. 2017;17(1):68. https://doi.org/ 10.1186/s12883-017-0853-y.

98. Cruz R, Lenz M, Belter L, Hobby K, Jarecki J, Smart T. The voice of the patient report for spinal muscular atrophy. 2018. https://www.curesma.org/wp-content/uploads/2018/01/SMAVoP-for-publication-1-22-2018.pdf. Accessed 6 Nov 2019.

99. Food and Drug Administration. Methods to identify what is important to patients \& select, develop or modify fit-for-purpose clinical outcomes assessments. White Oak; 2018. https://www. fda.gov/drugs/news-events-human-drugs/patient-focused-drugdevelopment-guidance-methods-identify-what-important-patie nts-and-select. Accessed 6 Nov 2019.

100. Klug C, Schreiber-Katz O, Thiele S, Schorling E, Zowe J, Reilich $\mathrm{P}$, et al. Disease burden of spinal muscular atrophy in Germany. Orphanet J Rare Dis. 2016;11(1):58. https://doi.org/10.1186/ s13023-016-0424-0.

101. Shieh P, Gu T, Chen E, Punekar R, Tan H. Treatment patterns and cost of care among patients with spinal muscular atrophy. In: Cure SMA. 2017.

102. Khan KA, Petrou S, Rivero-Arias O, Walters SJ, Boyle SE. Mapping EQ-5D utility scores from the PedsQL generic core scales. Pharmacoeconomics. 2014;32(7):693-706. https://doi.org/10. 1007/s40273-014-0153-y.

103. Lloyd A, Gallop K, Thompson R, Vaidya S, Teynor M. Estimation of the health-related quality of life benefits of treatment for spinal muscular atropy (SMA). Value Health. 2017;20(9):A559. https://doi.org/10.1016/j.jval.2017.08.911.

\section{Authors and Affiliations}

\section{Noman Paracha ${ }^{1} \cdot$ Pollyanna Hudson ${ }^{2} \cdot$ Stephen Mitchell ${ }^{2} \cdot$ C. Simone Sutherland ${ }^{1}$ (D) \\ C. Simone Sutherland \\ 2 Mtech Access Limited, Bicester, Oxfordshire, UK}

simone.sutherland@roche.com

$1 \quad$ F. Hoffmann-La Roche Ltd, Basel, Switzerland 